\title{
The Effect of the New Normal Policy on Individual Behaviors
}

\author{
Nita Nurliawati*, Apriliani Nur Rachmawati, Fatih Nur Afifah Faiqoh, Maria Benedita Evelyne Angie, Veril Alwan \\ Hakim, Widaningsih \\ Politeknik STIA LAN Bandung \\ Bandung, Indonesia \\ *nita.nurliawati@poltek.stialanbandung.ac.id
}

\begin{abstract}
The outbreak of the Corona Virus Disease 19 (COVID-19) pandemic which has shocked not only the national scale, but the international is busy with the presence of this virus outbreak as well. This incident hinders the various activities of human life from various sectors. Therefore, the issuance of policies carried out by the government in dealing with this problem, one of which is the new normal. The new normal policy has a big impact in various lines of community life, in its handling it still needs close supervision. Many people do not understand the true meaning of new normal. This policy also resulted in changes in the structure of behaviour and conditions in society. This change is in the form of carrying out a health protocol consisting of $3 \mathrm{M}$, namely using masks, washing hands with soap or hand sanitizer, and maintaining a minimum distance of $\mathbf{1 . 5}$ meters which not only affects him, but also has the potential to affect the surrounding environment and society at a wider scale. However, the emergence of this policy can also have an impact on the mental health of the Indonesian people. Mental health is difficult to predict, but if it happens it will have a butterfly effect. For example, such as feeling bored in doing activities in the house which is very limited to the emergence of a feeling of being buried for a long time, later it will cause unexpected things negatively like ignoring health protocols when it is time to interact outside the home.
\end{abstract}

Keywords—public policy, new normal, mental health

\section{INTRODUCTION}

The Ministry of Health (Kemenkes) issued a transition protocol from PSBB to New Normal as a guideline for workers and the business community through decision number HK.01.07 / MENKES / 328/2020 dated May 20, 2020, concerning Guidelines for the Prevention and Control of COVID-19 in the Workplace and Office Industry in Supporting Business Continuity in Pandemic Situations. Impact of the implementation of the Government's New Normal policy system:

- The government must face two problems: restoration of health or national economic stability
- Changes in social behaviour of every individual in society due to lack of knowledge about the COVID-19 pandemic

Minister of National Development Planning (PPN) / Head of the National Development Planning Agency (Bappenas), Suharso Monoarfa conveyed indicators from WHO in implementing the New Normal scenario:

- Do not increase transmission or increase transmission or reduce transmission.

- Using health system indicators, namely how high the adaptation and capacity of the health system to respond to COVID-19 services.

- Surveillance is a way to test a person or group of people whether or not they have the potential to be infected with COVID-19 or not so that a massive test is carried out.

During any outbreak of an infectious disease, the population's psychological reactions play a critical role in shaping both spread of the disease and the occurrence of emotional distress and social disorder during and after the outbreak. Despite this fact, sufficient resources are typically not provided to manage or attenuate pandemics' effects on mental health and wellbeing. While this might be understandable in the acute phase of an outbreak, when health systems prioritize testing, reducing transmission and critical patient care, psychological and psychiatric needs should not be overlooked during any phase of pandemic management [1]. Research shows that having a mostly good attitude is complying with government advice regarding health protocols, but more than $80 \%$ of people are preoccupied with thinking about Covid-19. Information about covid-19 is widely circulating both on television, mass media and social media so that it makes people always think and worry about Covid-19. It is feared that this will have an impact on one's mental health. This study shows some of the impacts experienced with covid19 , namely difficulty sleeping $12.5 \%$, paranoia about Covid-19 infection $37.8 \%$ and feeling pressure due to social media by $36.4 \%[2]$. 


\section{Social Problem}

The New Normal Policy had a huge impact on the life order of the state and society. Not only in the health and economic sector, the mental condition of every community is also influenced by the New Normal policy to overcome the COVID-19 pandemic that has come suddenly and is unwanted. Being cooped up for too long and doing activities with strict limitations, makes people feel anxious and anxious. The pressure that has been felt in more than half a year has resulted in a sense of indifference and neglect of the boundaries set during the early days of the Covid-19 pandemic. Psychologist from Personal Growth - an organization that provides professional psychological services specializing in counselling and people development, Veronica Adesla, says saturation can make people lose their fear and take the Covid-19 'ah, just it'. At that time, a person does not perceive any threat of harm to himself. This statement was later strengthened by the statement given by Elly Malihah, a Social Observer from the Indonesian Education University (UPI), that humans cannot really be locked up. This attitude certainly does not happen without cause, there are several factors that influence it. The first factor, there is a different meaning between the government and the civilians.

"In fact, in our society, the socialization of government policies has not been fully socialized. There is a bit of confusion with some of the terms conveyed by the government, such as new normal and PSBB. The people's meaning is that the meaning of the government is different,"

Not a few people of, continued Elly, consider the new normal to return to normal conditions before the pandemic. In fact, the term means, people can do activities as usual but with strict health protocols. The public must also understand that the corona virus is still a threat. Elly expressed it in the Sundanese term "siga kuda lepas dina gedogan" (like a horse that is loose from its stable). The second factor, Elly said, is that people find it difficult to vent their saturation in a safer way because of the lack of public facilities, such as city parks with sports facilities and playing facilities in their neighbourhoods. Then, as well as can be prevent in order to avoid the mental health effects of the COVID-19 infection, people need to avoid excessive exposure to COVID-19 media coverages, maintain a healthy diet and positive lifestyle, and reach out to others for comfort and consolation that the situation will soon be contained. Everyone should maintain a sense of positive thinking and hope and take personal or group time to unwind and remind the self that the intense feelings of fear, panic, and anxiety will fade. Additionally, seek information from reputable government sources for information and avoid the spread of erroneous information on the internet [3]

\section{RESEARCH OBJECTIVES}

- To find out or understand what New Normal Policy is

- To find out how the impact of policies on society in the implementation of New Normal Policy
- To find out how the community's response and solutions to the implementation of New Normal Policy

\section{REVIEW OF THEORY}

Within the implementation of this New Normal policy, the government enforces all Indonesian people to carry out activities while still implementing health protocols. The following are important things that need to be done in order to face the new normal policy. It is also recommended if you are not in good condition, should not do activities outside the home. The thing that must be done is to always wear a mask, keep your distance, and using hand sanitizer in the time has indicated the time to go straight home and carry out health protocols, bring supplies for lunch, and if you feel unfit, permission not to work. According to Helmi [4] that when a person experiences an adaptation process, their behaviour is marked by a contradiction between tolerance to pressing conditions and feelings of dissatisfaction so that people will carry out the selection process on the basis of rational considerations, including maximizing results and minimizing costs.

\section{A. Stimulus Response Theory}

Based on the Stimulus Response Theory or SR theory, it shows that communication is an action-reaction process. Such as communication theory according to experts, mass communication theory, mass media effect theory and agenda setting theory. In mass communication, it means that the stimulus given is in the form of a message, and of course the response given by the public will vary. This means that this model assumes that verbal words, non-verbal cues in verbal communication, and certain symbols will stimulate other people to respond in a certain way. This pattern can be accepted negatively or positively depending on how the individual responds. In response theory, there are elements that cannot be separated. The three elements are message (stimulus), communicant (organism) and effect (response). The presence of the Covid-19 virus is a pandemic that is unwanted by the entire community and occurs in an unknown time. This is an element of the message given. Then the government provides various information developments regarding the spread of the covid-19 virus through various media. The spread of the virus has made the economy unstable. Various activities began to be stopped and carried out in their respective homes. Entire communities experience unpredictable panic, ranging from large-scale purchases of food items for reasons of supply to suspicious individuals' behaviour.

\section{B. Planned Behavior Theory}

Regarding behaviour, Theory of Planned Behaviour has the aim of understanding motivational influences on behaviour that are not under the control or will of the individual himself. The theory provides a framework for studying attitudes toward behaviour. The public believes that implementing health protocols is one way to deal with the Covid-19 pandemic. The application of the protocol is then evaluated and states that in 
this way it can reduce the positive number of Covid-19. Every individual decides whether to follow the health protocol or not, it has an impact on the environment. Each individual is given the freedom to believe in the problem or not. However, from the application of health protocols each individual can be seen from his care in maintaining health, both health for himself and others.

To find the root of the problem, you can use Iceberg Theory. This theory makes it easier for parties to search for data as well as the results made to provide one colour in the problem, because the discussion is structured (not out of theme). In the case of the Covid-19 pandemic, every individual in society is afraid and anxiety every time they listen for news related to the case. The total number of deaths due to Covid-19 is increasing. This is caused by insufficient and inadequate facilities (isolation rooms), a decrease in the number of medical workers, a lack of knowledge about the Covid-19 virus, and a lack of public discipline in implementing health protocols. The shortage of medical facilities and services is caused by the government's failure to determine priorities.

\section{RESEARCH METHODS}

Information collection for this survey was carried out by distributing questionnaires through social media, such as groups WhatsApp and Instagram. This survey is aimed at the general public, consisting of 100 students, 19 educators, 9 private employees, 5 self-employed, 5 job seekers, 1 IRT and 1 civil servant. There are two questions that form the main line in the research discussion, namely "Do you (the respondent) know the term New Normal? And "How do people around you respond to New Normal?".

From the results of the first answer, it states that of the 140 respondents it shows that 98.6 percent of respondents already know the term New Normal, and around $1.4 \%$ do not know the term New Normal. This shows that the socialization of the policy New Normal to the wider community has been carried out well. However, there are still people who do not understand the policy. Public ignorance is still the main task of the government to continue to provide socialization about the policy. Although the percentage of respondents who do not understand the New Normal is relatively small, the government cannot ignore it. Because it is possible, by prioritizing or paying more attention to those who already understand, it will result in an increase in the number of people who do not understand the policy New Normal.

The result of the second question is about 7.9 percent of respondents said that the environment around the respondents was very concerned about responding to the policy New Normal. However, around 45 percent of respondents said that the environment around them was normal towards the New Normal policy. Comparison of this document study shows that the implementation of the policy New Normal by the community has not been maximal. The reason is this can be bad for the surrounding environment. With a normal feeling in implementing this policy it can lead to various bad perceptions or views, such as suspecting one another. Because there are not a few cases that have occurred in the vicinity of a residential area, where each other has very high suspicion.

The result of our questionnaire shows similarity to the research titled Immediate psychological responses and associated factors during the initial stage of the 2019 coronavirus disease (COVID-19) epidemic among the general population in China by Wang et al, cited from the International Journal of Environmental Research and Public Health 2020 [5]. According to that research, out of 1,210 respondents from 194 cities in China in January and February 2020 found that $54 \%$ of respondents rated the psychological impact of the Covid-19 outbreak as moderate or severe; $29 \%$ rated moderate to severe anxiety symptoms; and $17 \%$ moderate to severe depressive symptoms. Social media exposure or frequent exposure to news/information concerning COVID-19 was positively associated with symptoms of anxiety and stress. With the unpredictable situation and a lot of unknowns about the novel coronavirus, misinformation and fake news are being easily spread via social media platforms, creating unnecessary fears and anxiety.

In an article by $\mathrm{W}$. Cullen about Mental health in the Covid-19 Pandemic published by Oxford University Press in 2020, people with established mental illness have a lower life expectancy and poorer physical health outcomes than the general population [1]. As a result, people with pre-existing mental health will be at increased risk of infection with Covid19 and increased risk of negative physical and psychological effects stemming from the pandemic.

The theory of planned behaviour is an extension of the theory of reasoned action made necessary by the original model's limitations in dealing with behaviours over which people have incomplete volitional control. In theory of reasoned action, a central factor in the theory of behaviour is the individual's intention to perform a given behaviour. Intentions are assumed to capture the motivational factors that influence a behaviour; they are indications of how hard people are willing to try, of how much of an effort they are planning to exert, in order to perform the behaviour. In other words, intentions are one of the roots of behaviour. However, every person has the ability to choose whether they are going to perform or not to perform the behaviour.

We used the theory of planned behaviour to understand motivational influences on the behaviours that are not under the control or will of the individual themselves. The public believes that implementing the health protocol is one of a few ways to deal with Covid-19 pandemic. The implementation is then constantly evaluated in hope to reduce the raising numbers of cases. Because each individuals have their own beliefs of behaviour, subjective norms, and normative beliefs, they decide their own action whether to follow the health protocol or not. 


\section{CONCLUSION}

Pandemic COVID-19 has given the changes to social life, and the change in the application of order of the new normal changing patterns of social interaction should be based on a health protocol safe from the spread COVID-19. These changes are related to the interaction of individuals with their environment which consists of the nuclear family environment, family environment, workplace environment, basic needs fulfilment environment and entertainment environment. In the context of interaction in the family environment, each family member must understand and practice the new norms by applying healthy and clean-living habits in the home. In the context of social interaction in the public space, starting from interactions with neighbours and colleagues, it is oriented towards social interactions that maintain social distancing from one another and use mouth masks. This change is based on vigilance to prevent the spread of COVID-19.

The existence of ignorance and lack of understanding has an effect on the implementation of the new normal in general and health. The capacity for each individual varies especially mental strength. Mental health that comes from the soul is difficult to predict, for example the feeling of saturation has a very big influence in determining behaviour, which reflects in the responses of the respondents who are influenced by feelings of saturation. Ranging from low to acute levels that interfere with other activities such as online distance learning and other activities. The need for mutual assistance is increasingly mushrooming, until many people are not aware or forget that this epidemic is still there. So that when we realize it more deeply, we protect the environment and ecosystem together with the living things in it.

The implementation of the new normal order is empirically faced with several challenges, namely regarding the content of the order policy new normal which contains health rules or protocols that must be implemented, concerning parties appointed to carry out the order new normal, and concerns the community as the target group. WHO must obey the rules new normal that have been made. Compliance and adherence to this new normal policy will have implications for a new social life based on the awareness of every individual to prevent the spread of COVID-19. In addition, implementing the new normal when the spread curve is still in an upward trend is something you should not do, this policy will only make the number of positive cases and the death rate related to COVID19 continue to increase. In line with that, the government has also not improved the pattern of handling COVID-19 in various lines of community life. All these problems then have an impact on the Indonesian economic sector which is currently getting worse.

\section{SUGGESTION}

The government must look at the reproductive level of the COVID-19 outbreak, emphasize more on socialization from the health office or local government about this new normal to the public. And the most important thing is the obedience of society in following the rules of the new normal itself. Because people tend to be indifferent to the advice given, to be more orderly in maintaining distance. Because there are still many who have not implemented it, such as clustered in one place. So do not let this rule fail to apply.

\section{REFERENCES}

[1] W. Cullen, G. Gulati, and B.D. Kelly, "Mental health in the COVID-19 pandemic," QJM: An International Journal of Medicine, vol. 113, no. 5 , pp. 311-312, 2020

2] D. Roy, S. Tripathy, S.K. Kar, N. Sharma, S.K. Verma, and V. Kaushal, "Study of knowledge, attitude, anxiety \& perceived mental healthcare need in Indian population during COVID-19 pandemic," Asian journa of psychiatry, vol. 51, pp. 102083, 2020.

[3] K. Shah, D. Kamrai, H. Mekala, B. Mann, K. Desai, and R.S. Patel, "Focus on mental health during the coronavirus (COVID-19) pandemic: applying learnings from the past outbreaks," Cureus, vol. 12, no. 3 , 2020 .

[4] A.F. Helmi, "Konsep dan teknik pengenalan diri," Buletin Psikologi, vol. 3, no. 2, pp. 13-17, 1995.

[5] C. Wang, R. Pan, X. Wan, Y. Tan, L. Xu, C.S. Ho and R.C. Ho, "Immediate psychological responses and associated factors during the initial stage of the 2019 coronavirus disease (COVID-19) epidemic among the general population in China," International journal of environmental research and public health, vol. 17, no. 5, pp. 1729, 2020. 